\title{
DOGUMENTO
}

Políticas públicas, cooperativismo

y desigualdad social: el caso

costarricense durante el apogeo

del Estado de Bienestar 


\section{Políticas públicas, cooperativismo y desigualdad social: el caso costarricense durante el apogeo del Estado de Bienestar}

Investigador: Sergio Salazar Arguedas'

\section{Resumen}

El cooperativismo costarricense se vio fuertemente fortalecido en la segunda mitad del Siglo XX debido a su rol activo para diversificar la economía local. De la mano de un creciente número de instituciones descentralizadas, las cooperativas ejecutaron políticas públicas en cuatro ejes principales: café, electrificación rural, ahorro y crédito y agro. Las experiencias más exitosas dan cuenta que la combinación de la acción colectiva y la gestión colectiva en esas organizaciones es fundamental en el desarrollo de los territorios.

El presente artículo ofrece una visión general de las políticas públicas impulsadas desde el Estado costarricense entre 1949 y mediados de los años ochenta del siglo pasado en materia de cooperativismo, en el contexto de la cooperación y el sistema mundo.

Palabras clave: Cooperativas, políticas públicas, igualdad.
Abstract
Costa Rican cooperativism was strongly strengthened in the second half of the 20th century due to its active role to diversify the local economy. Hand by hand with a growing number of decentralized institutions, cooperatives implemented public policies in four main areas: coffee, rural electrification,

\footnotetext{
1 Investigador. Sociólogo experto en cooperativismo y desarrollo. Ha realizado investigaciones sobre los aportes de las cooperativas en zonas rurales, demostrando que el modelo cooperativo multiplica hasta en seis veces los beneficios de las empresas mercantiles. Es profesor de la Escuela de Relaciones Internacionales de la UNA y colaborado en el ICAP como docente y en trabajos de graduación. Actualmente es el gerente de Desarrollo Estratégico del Instituto Nacional de Fomento Cooperativo en Costa Rica.
}

savings and credit, and agriculture. The most successful experiences show that the combination of collective action and collective management is fundamental in the development of territories.

This article offers an overview of the public policies promoted by the Costa Rican State between 1949 and the mid-eighties of the last century in terms of cooperativism, in the context of cooperation and the world system.

Key words: Cooperatives, public policy, equality.

Recibido: 15 de marzo de 2021

Aceptado: 03 de mayo de 2021

DOl: hłtps://doi.org/10.35485/rcap80_8 


\section{Introducción.}

El sistema mundo económico vigente ha sido desarrollado sobre las bases firmes de la expansión geográfica, la explotación constante de recursos productivos y una incesante autoreproducción desde la extracción de plusvalor. Bajo esas premisas dicho sistema ha generado una profunda distribución desigual del ingreso, dejando tras de sí una estela estructural de difícil atención que divide el mundo entre centro- periferia, desarrollo-subdesarrollo y riqueza-pobreza, todas categorías que describen la realidad del sistema en su esencia.

En esa dinámica dualista y dicotómica por naturaleza, el cooperativismo ha levantado su mano como una opción viable para atender la desigual distribución de la riqueza producida desde los inicios de la primera revolución industrial inglesa. No en vano el cooperativismo se desarrolla con más fortaleza en esa época como una alternativa principalmente para los sectores populares excluidos y explotados en el sistema.

Sin embargo, los valores que rigen ese sistema económico a menudo subsumen la doctrina cooperativa en su dinámica individualista, concentradora y ahistórica, facilitando que la alternativa de distribución se diluya en el espejismo de la rentabilidad y la competitividad de las empresas mercantiles, destruyendo identidad y capacidades grupales en el territorio.

En el contexto de esa dinámica de paradigmas empresariales por la generación de mejores condiciones de vida para la población, el mundo actual se divide entre acumular y distribuir, entre lo individual y lo colectivo y entre lo inmediato y el largo plazo; mientras tanto, el problema de la desigualdad crece como un componente estructural en el sistema económico alrededor del mundo.

El presente artículo busca profundizar en esas dicotomías del mundo moderno, la importancia de la cooperación en la vida cotidiana, y sobre todo, la importancia que las políticas públicas en materia cooperativa tuvieron en Costa Rica con el desarrollo del Estado de Bienestar desde 1949 y hasta los años ochenta del siglo pasado, fecha en que el país enfrentó cambios importantes que debilitaron el impacto del aparato estatal debido a la apertura comercial y a cambios estructurales en el movimiento cooperativo que lo hacen objeto de otro tipo de análisis en la forma de articular y de ejecutar la política pública nacional cooperativa.

\section{Cooperación y cooperativismo: bases de la vida en social solidaria.}

La cooperación ha estado presente en la humanidad como una condición inherente de la vida social y la sobrevivencia humana. No existe sostenibilidad en la vida humana o natural alejada de la cooperación entre los seres vivos porque un concepto como competitividad, desarrollado sin cooperación; arrasa con todas las posibles proyecciones de vida en todo nivel.

Cooperar es producir vida, extenderla, mejorarla, procurando atender los requerimientos societarios o sistémicos de sus partes con algún tipo de rezago, así como de sus agentes más favorecidos en el desarrollo. Cooperar es garantizar condiciones dignas de vida para los seres vivos, sin atentar contra el desarrollo de la vida en el tiempo y el disfrute de otras generaciones.

El mantenimiento de la vida por grupos humanos desde el propio paleolítico requirió fuertes dosis de cooperación para atender las diversas funciones que el entorno natural imponía, naciendo con ello la división del trabajo y la especialización a lo interno de los grupos humanos. Con la cooperación se da la humanización de la especie humana, pues "el hombre pasó de un estado puramente animal a un plano eminentemente social y la condición humana se reflejó en el hecho de vivir en sociedad"' (Aguilar y Fallas 1990, p.33).

Esa primaria división del trabajo generó especialización, conocimiento del medio natural y de las condiciones cambiantes para la domesticación de los factores diferenciados, trayendo consigo tecnología, herramientas y estrategias para el asentamiento humano en un territorio. El paso de seres humanos nómadas hacia grupos sedentarios facilitó la conformación de grupos sociales y de 
estructuras de vida colectiva que bajo el amparo de la cooperación permitieron establecer las bases de la vida social como la conocemos en la actualidad.

Así las cosas, siguiendo a Aguilar y Fallas (op. cit.), las incipientes sociedades sedentarias generaron que "los hombres se hicieron diestros agricultores, las mujeres adquirieron pericia en labores manuales, mientras que los niños y ancianos cuidaban los animales domésticos y los campos cultivados"' (p.35), a la vez que dichas sociedades empezaron a conocer el excedente, componente fundamental que en nuestras sociedades modernas es la base de la organización social, la cultura y la desigualdad.

Esas primeras sociedades sedentarias utilizaron el excedente colectivo para beneficio del propio grupo social, manifestado como reservas de granos, frutos, alimentos y en general cosechas que se utilizaban en tiempos de baja producción de alimentos o cuando descendían los productos de la caza y la pesca. La funcionalidad del excedente estaba marcada para atender la sobrevivencia del colectivo, donde su carácter cooperativo era esencial.

Enrique Dussel (2014), denomina a esas sociedades antiguas como sociedades equivalenciales en vista que, bajo el precepto de la cooperación, se administraban los resultados de los productos sociales de manera colectiva, bajo el principio de sostenibilidad de la vida. Por ello, muchas sociedades no conocieron el concepto de mendicidad o de pobreza, sobre todos las ancestrales.

Los grupos equivalenciales tenían profundas raíces solidarias, pues para el autor (op.cit.) en ausencia de acumulación de excedente o no existiendo del todo, socialmente estaba definido como propiedad común, por tanto; no necesariamente había explotación política o dominio de un grupo sobre otro (p.54). Dichos grupos humanos establecieron que el producto excedentario se utilizara para consumo en el propio sistema, lo que generaba una economía equivalencial donde destacaron gestores comunitarios del excedente, normalmente las personas con mayor experiencia y edad en el grupo encargados del trabajo guía del colectivo (Ibid.p.63).
No obstante, lo anterior, la complejidad de esas sociedades poco a poco generó que a lo interno de los grupos humanos se establecieran mecanismos de diferenciación social debido a la acumulación de bienes materiales y dinero, trayendo consigo que el poder y las decisiones comenzaran a formar parte de la dinámica creciente de ciertos grupos por encima de otros. El tránsito de sociedades equivalenciales hacia sociedades no equivalenciales, como las denomina Dussel irrumpe el escenario de la vida en sociedad y se complejiza conforme la ciencia y la técnica facilitan la extracción de las formas diferenciadas del excedente de cada grupo humano, sin importar el espaciotiempo en que se materializan.

Para Dussel (2014):

Ese sistema no- equivalencial se instaló en un momento histórico que comenzó en Mesopotamia, en Egipto y en las costas orientales del Mediterráneo, pero igualmente en la India en torno a río Indo y en la China en el curso y desembocaduras de sus grandes ríos. También en América los hubo en Mesoamérica y los Andes (p.54).

Los desarrollos culturales más importantes en esas sociedades se dieron gracias a la tecnología y la división del trabajo. El nacimiento de las ciudades, la ciencia, los intercambios comerciales, la navegación, incluso la guerra, son productos de sociedades no equivalenciales que, por consiguiente; vieron nacer grupos políticos y de poder económico ligados con el apropiamiento del excedente, la expansión territorial y la toma de decisiones en materia política y económica.

Ese proceso de expansión se mantuvo en prácticamente todas las culturas del mundo donde en la mayoría de los casos tuvo como objetivo el apropiamiento del excedente generado por otras sociedades, respetando en la mayoría de los casos las culturas sometidas a dominación; hasta que la modernidad europea irrumpió como un proyecto societario de alcance mundial no solo en lo económico sino en lo cultural, que implicaba formas más desarrolladas de explotación y dominación.

En efecto, la sociedad no equivalencial según el concepto de Dussel, que nace con 
la modernidad europea hacia 1462 según Wallerstein (2013), trae consigo un proyecto expansionista como en ningún otro momento de la historia se había generado por sociedad alguna.

Sobre la base de una colonización cultural y del apropiamiento sistemático del excedente, esa sociedad capitalista presenta la característica esencial de lograr transformarse en sistema mundo cuando ese excedente cambia el uso histórico que venía generando "con el objetivo o intento primordial de su autoexpansión" (Wallerstein, op. cit. p.2), con ello, es un sistema que requiere ampliar sus límites geográficos y económicos constantemente para apostar a su sobrevivencia en el corto y largo plazos.

En segundo lugar, estableció una división internacional del trabajo (más estandarizada globalmente) gracias a la modernización de ciclos de procesos (ciclos del capital) los cuales modernizó al mercantilizarlos (procesos de intercambio, producción, distribución, inversión) por medio de su incorporación al mercado (Ibíd., pp.3 y 4). En esa división estableció funciones para países y regiones sobre el marco de lo que se ha denominado centro y periferia, donde claramente el centro es definidor de roles, lo cual favorece la acumulación de excedente (riqueza), la implantación de tecnología y dirección de los negocios.

Finalmente, el sistema se fortalece gracias a uno de sus principios fundamentales como es el que " (...) esté gobernada por el intento racional de maximizar la acumulación" ' (Ibíd., p.6). En efecto, ese eje fundamental es el que permite la extracción y la acumulación de ámbito mundial, trayendo consigo que la desigualdad y la acumulación, el desarrollo y el subdesarrollo, así como el centro y la periferia sean categorías inherentes del sistema.

El contexto en el que nace y se consolida el cooperativismo en la primera mitad del siglo XIX en Inglaterra es ese sistema mundo de alcance global que potencia la concentración de riqueza en pocas manos y genera desigualdad en los territorios que subsume en esa dinámica. Esos elementos los genera gracias a una técnica y a una ciencia que facilitan el apropiamiento del plusvalor y a una estructura de relaciones que lo permite, denominada centro-periferia.

Las ciudades que poco a poco se fueron consolidando como producto del sistema, se transformaron en nuevos espacios sociales de explotación de hombres, mujeres, niños y niñas con jornadas laborales de hasta 18 horas. Literalmente, miles de personas dejaron la vida en telares, talleres de producción, construcción de líneas de ferrocarril, apertura de caminos y carreteras con la finalidad de hacer crecer las condiciones necesarias de expansión del sistema mundo. Otro tanto de personas formó parte de los procesos de migración que desde la Europa central forjaron destino en Norte, Centro y Sudamérica o en Oceanía.

Mientras la riqueza se acumulaba en pocas manos entre los grupos que disponían de medios de producción para la instalación de sus empresas; la pobreza y la desigualdad social hundían a la mayor parte de la población en condiciones que no alcanzaron ni el mínimo para la subsistencia. Es en ese contexto en el que nace el cooperativismo como una alternativa social y económica de distribución de riqueza y generación de condiciones dignas de vida para la población.

Para Juan A. Huaylupo, (2007), el cooperativismo no parte de una base de personas para la generación de mejores condiciones de vida para ellos, sino como una respuesta a ese sistema que desde sus inicios generaba subproductos de desarrollo como parte de su dinámica interna:
El cooperativismo, no nació históricamente para atender exclusivamente las necesidades de sus miembros, fue una respuesta popular ante las condiciones imperantes de un sistema excluyente e inequitativo existente en cada sociedad. El compromiso social del cooperativismo es histórico y está materializado en principios que aún tienen vigencia en el presente globalizado (pp.77-78).

En efecto, las cooperativas mantienen su vigencia en el sistema mundo porque los principios que rigen ese sistema se mantienen intactos en su esencia, y en el tanto que persista el desarrollo desigual seguirán siendo 
una opción viable para la población, sobre todo la más necesitada. Los momentos de cada grupo humano para el desarrollo de una cooperativa son establecidos por las particularidades de su cultura y madurez de su vida colectiva.

Las cooperativas con empresas asociativas que nacen en un espacio-tiempo determinado. Para Huaylupo (2005) ese espacio-tiempo se genera en la interacción de personas en el contexto histórico en que conviven: "No existe tiempo sin sociedad. Las magnitudes de tiempo, sin el reconocimiento social del devenir de los acontecimientos, es un conjunto vacío de significados aislados"' (p.34). Esos significados que los colectivos crean, condensan la solidaridad para la atención de sus necesidades humanas, haciendo del tiempo y de la propia sociedad un imaginario compartido diferente en el devenir del sistema dominante.

La importancia histórica del cooperativismo radica en ser un producto social que sobre la base de un capital humano que denominamos capital social, se generan mejores condiciones de vida en un territorio, que sobre bases colectivas de solidaridad, distribuyen mejor la riqueza y atiende espacios de interés público sin serlos en su totalidad.

\section{Políticas públicas y cooperativismo.}

Los antecedentes del cooperativismo latinoamericano se encuentran en el legado de las culturas autóctonas, las cuales tenían en la solidaridad la base de su avance social, político y económico.

Jorge Coque Martínez (2002), advierte la presencia de cajas de ahorro y crédito en México y en Venezuela como resultado de organizaciones cooperativas de origen religioso durante los Siglos XVII y XVIII. Ese origen ideológico, según Pineda et al (1994), citado por Coque (2002), estaba marcado por un pensamiento socialista, utópico y asociativo europeo, en periodos previos de a la formación de la cooperativa de Rochdale en Inglaterra, como claro apoyo a la actividad económica que se generaba en el continente en beneficio de las clases populares.
Esa influencia de pensamiento europeo, según tendencias de la (OIT, 1998) citado por Coque (2002), se marcaron también por migrantes llegados a Argentina y Brasil (principalmente italianos, franceses y alemanes), en Paraguay (dominantemente alemanes) y en Chile y Perú (principalmente de Inglaterra). También, se mezclaron con formas internas de pensamiento social como las sindicales, las mutualistas, el consumo y el ahorro y crédito, así como los servicios en países como Paraguay, Argentina o Chile; donde se dio paso a un pensamiento latinoamericano con intelectuales de Perú, Ecuador y Costa Rica (p.151).

Desde esos antecedentes, en el marco de desarrollo que impone el sistema mundo, el cooperativismo ha venido evolucionando desde la segunda mitad del siglo XIX gracias a la expansión del intercambio intelectual sobre el tema en revistas y periódicos nacionales, gracias a procesos naturales de organización social producto de esa circulación de ideas entre sectores sociales; y finalmente, por la articulación de políticas desde gobiernos nacionales para atender necesidades en el desarrollo.

Los fines sociales fueron marcados mediante procesos de asociatividad espontánea entre gremios productivos como respuesta a la constante explotación a la que estaban siendo sometidos, tanto en el desempeño de funciones como peones o como productores independientes en las diferentes cadenas de valor. Actividades como el café, la caña de azúcar, el maíz, el comercio y algunos servicios, visualizaron en la incipiente doctrina cooperativa formas solidarias de distribución de la riqueza y eliminación de la explotación que, no obstante; encontraron falta de apoyo político y legislación para su despegue en la segunda mitad del siglo XIX.

En los ámbitos político y económico, la promoción de cooperativas desde varios gobiernos nacionales respondió a la necesidad de articular procesos de inserción económica ligados con reformas agrarias impulsadas con la finalidad de atender luchas campesinas y crecientes procesos de deterioro social a lo interno de los países. 
No en vano autores como Picado y Silva (2002), identifican las cooperativas con marcados contenidos políticos (p.10), donde esas organizaciones y otras formas asociativas fueron actores principales en las reformas agrarias en el continente, utilizadas por medio de políticas públicas para incorporar sectores campesinos al sistema mundo económico.

Uno de los estudios clásicos del cooperativismo del tercer mundo es sin duda el proyecto denominado: Cooperativas rurales e instituciones relacionadas como agentes de cambio, dirigido por UNRISD, y traducido en español como Cooperativismo: su fracaso en el tercer mundo. En dicho estudio se incluyó 40 estudios de casos en Sri Lanka, Irán, Bangladesh, Camerún, Ghana, Kenia, Tanzania, Túnez, Uganda y Zambia y Colombia, Ecuador y Venezuela. (Cepal, 1985, p. 6) concluyendo categóricamente que:

Las cooperativas rurales en las regiones en desarrollo producen en la actualidad pocos beneficios a las masas de habitantes más pobres de tales áreas y no pueden considerarse, en términos generales, como agentes de campo y desarrollo para tales grupos (p.6).

Orlando Falls Borda dirigió los estudios en los países de América Latina y concluye que fueron razones políticas las que motivaron el apoyo estatal a las cooperativas, buscando eliminar las luchas campesinas debido a las crisis económicas, por ello la promoción de las cooperativas esté tradicionalmente asociada con periodos de violencia y depresión como norma general (p.6)

Otro de los hallazgos más importantes de Falls Borda muestra que las cooperativas no cumplieron la función de agente de cambio en vista que poblaciones asociadas no tenían propiedad ni acceso a recursos para generar beneficios personales provenientes y beneficiarse de la cooperativa. En otro tipo de cooperativas, como las de afiliación restringida, se mejoraron las condiciones de la población; produciendo efectos contrarios a lo planificado con la promoción de cooperativas (p. 6).
Pese a lo anterior, según información de la Cepal (1985), a mediados de esa década perdida, Latinoamérica registró un total de 32.441 cooperativas las cuales sumaron casi 18 millones de asociados, lo que representó un peso relativo del $16 \%$ de la población económicamente activa. Destaca que entre las actividades económicas más relevantes se tienen las agropecuarias con el $34 \%$, las de ahorro y crédito con el $13 \%$ y las de vivienda con el $11 \%$ del total. Sin embargo, como es de suponer, las de mayor cantidad de base asociativa fueron las cooperativas de sectores como el de ahorro y crédito con el $33 \%$ de la membrecía, servicios varios con el $20 \%$, las cooperativas de consumo con el $16 \%$ y las de giro agropecuario con el 12\% (p. 9-12).

Actualmente, el cooperativismo latinoamericano, pese a no contar con bases de información sólidas, tiene gran impacto económico y social gracias al desarrollo de legislación nacional, soporte económico y crediticio, así como la conformación de redes de apoyo entre organizaciones sectoriales o regionales.

En Costa Rica el cooperativismo ejerció un papel fundamental en la modernización del Estado en 1949, en la diversificación de la economía interna y sobre todo, en el desarrollo de extensos territorios rurales que no tenían electricidad, caminos e infraestructura productiva.

La arquitectura intelectual de ese estado de bienestar tuvo su basamento en el pensamiento de Rodrigo Facio, el cual consideraba que el país tenía una cultura de bajo desarrollo pues "al consumirse la época colonial, Costa Rica presentaba el aspecto estático de una economía cerrada y atrasada y escasamente satisfecha en sí misma"' (1978. p 33), aspecto que los cultivos importantes como el café y la caña de azúcar no lograron mejorar.

Las rectificaciones económicas de Facio proyectaron que las decisiones en materia económica estuvieran en manos del Estado, donde los beneficios de la participación de nuevos actores sociales y económicos recayeran en los tradicionales grupos sociales con menores oportunidades, los cuales, de la 
mano de las cooperativas, se transformaran en pequeños propietarios. En palabras del autor, la estructura estaría conformada por:

- Una base social dedicada a fomentar la inmigración controlada, organizar colonias por regiones, formar cooperativas de crédito, producción para el incremento de compras y ventas y con ello el fomento del consumo; así como el logro de acuerdos regionales entre cooperativas de productores y consumidores.

- Base económica con impuesto progresivo sobre la propiedad inculta, expropiar y asignar tierras, construcción de caminos, organizar la producción, creación de almacenes de depósito del Estado con capacidad de otorgar crédito a productores para dinamizar el intercambio de productos agrícolas.

- Base técnica y científica que organice la agricultura en torno a las necesidades de la población, considerando el potencial de la riqueza vegetal, animal y mineral.

- Base de comercio exterior, promovida para la adecuación del funcionamiento de las exportaciones, tratados internacionales, tarifas y encargada de promover la diversificación y las áreas de la producción nacional (Facio, 1978, pp.173-174).

Bajo esa arquitectura, el estado de bienestar comenzó a generar política económica que encaminara el rumbo del país hacia una mayor distribución de la riqueza y diversificación económica. Para Rovira (2000), esas políticas se resumen en las siguientes:

- Diversificar la actividad económica en el mercado interno de productos.

- Facilitar una demanda interna creciente de productos para el mercado nacional.

- Nacionalizar la banca y con ello, facilitar crédito para pequeños productores.

- Democratizar el acceso a la tierra por medio de la promoción de cooperativas.

- Crear instituciones públicas que sostengan los cambios propuestos en cada sector.

- Aumentar el ingreso económico de las clases populares con el fin de incentivar la demanda interna.
La política social del Estado costarricense se fundamentó en la creación de cooperativas para la ejecución de los grandes procesos de desarrollo generados en el país. Dichas políticas se articularon mediante la dirección de las nacientes instituciones públicas que ejercieron roles de rectoría, de orientación técnica, de contraparte económica y de apoyo en el desarrollo de cooperativas. Los cuatro ejes de políticas públicas impulsadas desde el cooperativismo son los siguientes:

\section{- Cooperativas agrarias, impulsadas desde el Instituto de Tierras y Colonización ITCO primero y el Instituto de Desarrollo Agrario IDA después.}

Su misión fue la ejecución de las reformas agrarias pendientes en el país, la atención de conflictos sociales ligados con campesinos sin tierras y la coordinación con el aparato estatal creado con la finalidad de consolidar la colonización, los asentamientos y el desarrollo rural.

En procesos más recientes, esas instituciones crearon condiciones para la capacitación, el acompañamiento, la creación de mercados y el otorgamiento de crédito de manera independiente.

\section{- Cooperativas cafetaleras impulsadas por el Banco Nacional de Costa Rica (BNCR).}

En el contexto de la acumulación de poder que tenían los exportadores de café en el nivel nacional, los cuales controlaban desde la presencia en mercados internacionales, así como el financiamiento de la cosecha; las cooperativas fueron promovidas con el objetivo de democratizar esas cadenas de valor, distribuir los impactos de dicha actividad, desarrollar zonas rurales con poca infraestructura productiva y dinamizar las regiones. El banco cumplió funciones de gran importancia para la asignación de activos productivos entre las nuevas cooperativas, el acceso a crédito, capacitación y formación.

De manera complementaria, el Instituto del Café de Costa Rica (ICAFE) se encargó de desarrollar los componentes técnicos para incrementar la productividad y generar normativa para modernizar el sector en el 
contexto de una creciente presencia del producto nacional en mercados externos.

\section{- Cooperativas de electrificación rural impulsadas desde el Instituto Costarricense de Electricidad (ICE) y el BNCR, principalmente.}

Las limitadas posibilidades que tenía el Instituto Costarricense de Electricidad para electrificar todo el país en el corto plazo facilitaron que las cooperativas de café recién constituidas, de la mano de municipalidades y las comunidades rurales, articularan capital social comunitario tendiente a fomentar cooperativas de electrificación rural que movieron el aparato estatal para el impulso de políticas públicas capaces de atender esas necesidades en los territorios.

El Estado costarricense, como respuesta a esas iniciativas regionales, facilitó la búsqueda de cooperación internacional para traer capital de inversión y capacitación por medio del propio ICE, quien ha ostentado la rectoría de la energía en el ámbito nacional. Esas cooperativas rurales se constituyeron como fuertes herramientas de ejecución de obra pública las cuales desarrollaron importantes sectores rurales del país, y con ello; la modernización de la economía local.

\section{- Cooperativas de ahorro y crédito, con impulso del BNCR y de fondos internacionales como AID.}

Finalmente, las burocracias crecientes en los emergentes sectores privado y público se organizaron en cooperativas de ahorro y crédito con la finalidad de atender las crecientes demandas de crédito para sus necesidades y con ello incrementar la demanda interna, una apuesta del estado de bienestar desde 1949.

No obstante, ese cooperativismo también atendió importantes sectores productivos en zonas rurales que poco a poco empezaron a germinar. En efecto, cooperativas de ahorro y crédito afiliaron importantes sectores agrícolas que en comunidades rurales facilitaron el crédito para pequeños productores de café, caña de azúcar; en áreas como el comercio, el consumo, los servicios y la vivienda, como parte del desarrollo regional que se venia consolidando en el país. En muchos casos, el capital utilizado provino de fondos del programa Alianza para el Progreso como una muestra clara de política pública para modernizar la economía y brindar apoyo en el fortalecimiento de ese tipo de empresas.

En resumen, el aparato estatal creado desde el Estado de Bienestar en la Costa Rica de 1949 utilizó el cooperativismo como una plataforma para diversificar la economía, incrementar la demanda interna, desarrollar los territorios rurales y apostar por un incremento de los pequeños propietarios que fueron organizados alrededor de esas empresas.

En ese contexto, se puede afirmar que la incorporación del país en el sistema mundo pasa en gran medida por los beneficios que trajo consigo el sector cooperativo a la economía nacional, en una especie de cogestión de políticas públicas entre las instituciones públicas descentralizadas y las propias cooperativas, existiendo de por medio importantes procesos de construcción de capital social que explica el desempeño positivo de muchas zonas en la actualidad.

Por ello, con el fin de conocer de manera integral los resultados más importantes de ejecución de políticas públicas por medio del cooperativismo, es necesario desarrollar dos categorías de análisis fundamentales: por un lado, la acción colectiva y por el otro, la gestión colectiva.

Por acción colectiva conocemos el conjunto de habilidades sociales que desarrolla un grupo humano con la finalidad de satisfacer las necesidades que comparten de manera común. Esas habilidades fortalecen la gestión operativa del grupo tanto como su gestión afectiva, de ahí que las capacidades como la identidad, la organización, la comunicación, la planificación y la ejecución; son fundamentales para avanzar desde estadios menores de desarrollo hacia estadios superiores. Se debe indicar que esa acción colectiva es una etapa temprana de capital social pues fortalece el colectivo internamente antes de gestionar los cambios proyectados. 
Por otro lado, la gestión colectiva es el resultado de la acción colectiva, pues implica la forma estratégica y operativa en que el colectivo ha resuelto atender sus necesidades comunes. Los procesos de planificación, organización, dirección, control y seguimiento de la cooperativa bajo los principios mundialmente establecidos por dicho movimiento, es la etapa de gestión colectiva del grupo.

Siendo así, el cooperativismo puede definirse como aquellos procesos de interacción de acción colectiva y de gestión colectiva alrededor de una cooperativa, en cumplimiento de su objeto social para la atención de las necesidades de sus asociados.

Cuando solo hay acción colectiva estamos en presencia de una asociación activa que busca soluciones, pero no las materializa empresarialmente; mientras que con la sola presencia de gestión colectiva tenemos una empresa que no tiene un fin compartido, sino que genera beneficios que reparte entre unas cuantas personas.

Ante un escenario de cumplimiento de una sola de esas categorías, el cooperativismo no genera los beneficios a sus asociados ni en los territorios donde ejerce influencia ya que éstos se alcanzan al desarrollar condiciones estructurales de desempeño empresarial y asociativo a la vez. En palabras de Pierre Bourdieu "En la práctica, las relaciones de capital social solo pueden existir sobre la base de relaciones de intercambio materiales y/o simbólicas y contribuyendo además a su mantenimiento"' (2000, p.149). El cooperativismo es en sí mismo una manifestación avanzada de capital social que encuentra en la gestión colectiva las formas de generar y de distribuir riqueza y con ello, atender la desigualdad social.

En el contexto de esas categorías de análisis, se debe indicar que las políticas de promoción de cooperativas establecidas en el país desde el año 1949 fueron diferenciadas generando resultados diferentes. Los desarrollos más importantes dan cuenta que el capital social llevó al cooperativismo y no el cooperativismo al capital social, que la acción colectiva es primaria a la gestión colectiva en esas empresas y que cuando se ejecutaron esos procesos de forma complementaria se identificaron elementos concretos de diversificación, desarrollo, e impactos sostenidos desde las cooperativas.

Por ejemplo, el Banco Nacional tuvo una oficina y luego un departamento de cooperativas que ejercía funciones de rectoría en el nivel nacional relacionadas con la legalización, el registro, capacitación, financiamiento y seguimiento. Además, el banco facilitó procesos de construcción de acción colectiva en grupos de productores que querían mejorar su calidad de vida, pero no sabían como hacerlo en un principio. Las cooperativas aparecieron después como la opción a tomar por el grupo.

En gestión colectiva el Banco otorgó crédito a muchas cooperativas, pero mantenía representación en el consejo de administración con la finalidad de crear capacidades internas, preparar cuadros de reemplazo, así como valorar el avance técnico y financiero de las nuevas cooperativas promovidas. Toda una apuesta de acompañamiento y capacitación desde el Estado para la generación de capacidades entre la población.

Los sectores más beneficiados de esa política pública fueron los de las cooperativas de productores de café y las de electrificación rural, muchas de las cuales actualmente son potentes interfaces de desarrollo regional que mantienen activos procesos de identidad con alto impacto social.

Por otro lado, gran parte de las cooperativas del sector agro promovidas desde el ITCO y el IDA no contaron con procesos de acción colectiva. En la mayoría de los casos las cooperativas fueron promovidas con la finalidad de atender procesos de colonización y de desarrollo rural sin que esas bases asociativas respondieran a intereses comunes sino a designaciones desde las instituciones públicas, dando como resultado el interés prioritario en la parcela, la tierra o la finca antes que la articulación de empresas sólidas y consolidadas.

Finalmente, el sector de ahorro y crédito tendió a desarrollarse en espacios laborales compartidos, tanto desde el ámbito privado como el público, lo que facilitó la conformación 
de acción y gestión colectiva con el tiempo, desarrollando empresas que actualmente gozan de gran prestigio en el nivel nacional.

Otros procesos similares se dieron en torno de comunidades rurales de economías crecientes, trayendo consigo el desarrollo de empresas que históricamente ejercieron funciones importantes en materia crediticia para el apoyo de productores, comerciantes, trabajadores públicos y privados con altos índices de identidad local.

El resultado actual de la ejecución de esas políticas públicas permite identificar con claridad que las cooperativas que pasaron por procesos de acción colectiva y de gestión colectiva se han mantenido competitivas en el tiempo donde muchas de ellas alcanzan más de sesenta años de vida funcional. Mientras eso ocurre, muchos procesos que no alcanzaron esas dos fases de crecimiento se mantienen como cifras en la historia, pero no como cooperativas en marcha que en promedio no alcanzaron los 6 años de vida.

Por otro lado, el crecimiento que han tenido muchas de esas empresas cooperativas exitosas las ha llevado a evolucionar satisfactoriamente hacia procesos de representación política vía delegados en asambleas, acrecentando las formas eficientes de desarrollo en los territorios. La estabilidad en puestos gerenciales, la especialización de sus mandos medios y la participación activa de sus asociados en cuerpos sociales de gestión o de control, son características manifiestas de acción colectiva y de gestión colectiva.

Mucho de ese cooperativismo que nació con las políticas públicas del Estado de Bienestar costarricense se mantiene en las estadísticas mas relevantes en el nivel nacional. Para el año 2012, con información generada en el IV Censo Nacional Cooperativo del (Programa Estado de la Nación, 2012), que es el censo de más reciente data, a la fecha se registraron 594 cooperativas que agruparon un total de 887.335 personas asociadas. Los aportes en la economía nacional se resumen en los siguientes indicadores:

- El 21 \% de la población nacional se identificó como asociada a alguna cooperativa.
- El cooperativismo generó 21.632 empleos directos.

- Las cooperativas de electrificación rural registraron 708 mil beneficiarios.

- $\quad$ El 36,5\% de la producción nacional de café en manos de cooperativas.

- Se produjeron 56 mil toneladas de productos industrializados de la palma aceitera.

- Producción de 418 millones de litros de leche por la vía cooperativa.

- Un monto que alcanzó los 132 mil millones de colones en exportaciones.

- Un monto de 895.590.082.000 de colones colocados por cooperativas de ahorro y crédito.

- Un total de 10.113 millones de colones inversión social desde las cooperativas.

- Se registró el 14\% de las utilidades del sistema financiero nacional proveniente de cooperativas de ahorro y crédito.

- 674.801.957.000 en captaciones nacionales provinieron del sector de ahorro y crédito cooperativo.

- 9,2 por ciento de personas aseguradas en el país atendidas por cooperativas de salud.

- 218 centros educativos en el país cuentan con cooperativas escolares y estudiantiles.

- Existencia de 746 puntos de servicio de las cooperativas en el país (p. 11).

\section{Incidencia de las cooperativas en la desigualdad social.}

Como ha sido analizado, en Costa Rica el cooperativismo fue promovido por el Estado como una opción viable de política pública para diversificar la economía interna y modernizar varios sectores productivos desde mediados del siglo XX.

Debe hacerse notar que pese a que desde inicios de ese siglo los sectores populares fundaron cooperativas en sectores como vivienda, servicios, café y consumo; el cooperativismo comenzó a ser una realidad cuando el país generó legislación moderna en la materia, cuando apoyó esas organizaciones por medio de instituciones públicas para su desarrollo y cuando facilitó la construcción de capacidades entre la población asociada. 
En resumen, el cooperativismo costarricense fortalece su presencia en el país gracias a la articulación de políticas públicas para su desarrollo.

Esa materialización de la política pública no fue estandarizada ni respondió a una rectoría nacional que orientara el accionar para el sector cooperativo. En su lugar, dio respuesta a los ámbitos de acción de cada institución pública creada con la finalidad de que desde su gestión fueran ejecutadas las acciones para atender las poblaciones y las cooperativas.

Pese a lo anterior, debe reconocerse que las políticas públicas más desarrolladas en materia de cooperativismo atendieron las necesidades de la acción colectiva de las poblaciones que posteriormente optaron por las cooperativas como respuesta a sus necesidades ${ }^{2}$, y en ese nuevo estadio; las políticas fortalecieron la gestión colectiva cuando las cooperativas entraron en operación en los mercados nacionales o internacionales. De manera complementaria, esas políticas integraron las acciones técnicas que desde las instituciones públicas descentralizadas fueron creadas para desarrollar los diferentes sectores económicos, tanto en café, caña de azúcar, arroz, productos agrícolas, entre otros.

Los resultados obtenidos en el nivel regional destacan un crecimiento tanto en la productividad individual de pequeños productores como en la competitividad general de las propias cooperativas, pues mezclaron de manera integral las políticas públicas diseñadas para el sector productivo en el ámbito local. Ello explica porqué la incorporación de la economía nacional en el sistema mundo se vio fuertemente favorecida con el desarrollo de las cooperativas en los últimos setenta años.

Si se considera la conceptualización que Castelao (2009, p.34), citando a Vuotto (2008) realiza sobre el diseño de políticas públicas para empresas de economía social, el éxito de esas políticas mencionadas en Costa Rica se dio por la combinación de políticas sectoriales que promovieron el desempeño de

\footnotetext{
2 Debe indicarse que otros procesos de construcción de capital social rural fueron canalizados por otro tipo de iniciativas colectivas que la legislación costarricense permite, tal es el caso de las asociaciones de productores o las de desarrollo comunal que también han desarrollado proyectos productivos.
}

cooperativas en su sector, pero, sobre todo; la aplicación de políticas territoriales que facilitaron la atención integral de importantes regiones del país.

Las políticas sectoriales facilitaron la elaboración de estudios de factibilidad que determinaron la viabilidad de los proyectos desde las instituciones rectoras del sector público. Con ello se ejecutó una fuente importante de financiamiento con manejo de riesgos, se establecieron procesos de acompañamiento técnico para la toma de decisiones en consejos de administración, cuerpos sociales y gerencias; así como el desarrollo de procesos de capacitación en doctrina cooperativa, legislación cooperativa, gestión financiera, contable y financiera.

Territorialmente, las cooperativas se subsumieron en planes de desarrollo nacional que incluyeron temas como avales nacionales para inversión, mejoras de caminos, electrificación, asistencia técnica productiva con la finalidad de incrementar rendimientos individuales y mejorar la eficiencia empresarial. Formaron parte de políticas crediticias y de soporte estatal para garantías internacionales e inversiones productivas.

Todo lo anterior trajo consigo que, en los casos cooperativos exitosos regionalmente, se tengan registros de importantes redes estructurales de relaciones entre actores económicos locales, instituciones públicas, instituciones de gobierno local y empresas privadas, conformando un capital social sostenido en el tiempo que ha favorecido la creación y distribución de riqueza de gran importancia para la atención de la desigualdad social.

En casos documentados en la Región de Los Santos en Costa Rica, se ha demostrado que el desarrollo del territorio se debe en casi su totalidad al aporte de un capital social comunal que las cooperativas de productores de café y de electrificación rural, de la mano con las municipalidades y las fuerzas sociales, canalizaron con el aparato estatal nacional para apoyar el desarrollo. Ese complejo entramado de capital social territorial ha facilitado el establecimiento de procesos constantes de capitalización empresarial, lo que ha favorecido la diversificación de los 
servicios cooperativos hacia sus asociados, la eficiencia, la competitividad y los precios de sus productos.

Debe reconocerse que, pese a la articulación de diversos actores locales, es el cooperativismo, en presencia de condiciones estructurales de desarrollo, el que materializa los beneficios sociales a la población y el que emerge en el imaginario social como la fuente de distribución de riqueza entre los grupos humanos.

En épocas de gran incertidumbre en los mercados por la baja de los precios de las materias primas, las cooperativas han redistribuido recursos de las actividades superavitarias hacia las actividades de menor rentabilidad, un ejercicio empresarial que no sería posible en empresas mercantiles. Con ello se ha permitido la generación de mejores condiciones de competitividad para que los productores se mantengan en la actividad, se construyan condiciones de acceso a crédito que en otras instancias sería imposible su acceso y por la vía de la participación económica; se tenga acceso al ahorro en costos al recibir servicios que son financiados solidariamente.

Esas políticas empresariales, las cuales responden a los consejos de administración y asambleas, son una realidad porque se sustentan en visiones de desarrollo entre personas de la zona que proyectan altos niveles de identidad y compromiso, los cuales favorecen la dirección de la cooperativa con fines solidarios donde la equidad forma parte del catálogo de decisiones colectivas.

Aunado a lo anterior, el aparato estatal establecido para atender los sectores productivos en los territorios se ha percatado que la inversión de recursos económicos, técnicos o productivos es más eficiente si se cristaliza por medio de las cooperativas. Adicionalmente, se identifican más y mejores impactos cuando dichas organizaciones son empleadas como instrumentos de ejecución de políticas públicas, ya que la apuesta es por planes de desarrollo territorial que amplía el espectro del desarrollo, ampliando los niveles de cobertura de los servicios para la población.
En ese contexto, las cooperativas constituyen una fuente inagotable de posibilidades para la promoción de un desarrollo integral ya que construyen, sostienen y permiten la distribución de la riqueza con resultados más eficaces que los que pueda tener una empresa mercantil.

A menudo las cooperativas suelen ser más eficientes que el propio Estado en la ejecución de las políticas públicas debido a la cercanía e identidad que tienen con sus asociados, pero sobre todo; al valor agregado que potencia los beneficios sociales, gracias al capital social presente en esas estructuras, elemento fundamental en el desarrollo territorial.

\section{A manera de reflexiones finales.}

Así las cosas, la promoción de políticas públicas sectoriales y regionales promovidas desde el Estado costarricense por la vía de instituciones públicas descentralizadas con la finalidad de hacer crecer la producción local en el marco de empresas cooperativas altamente competitivas, fue la base desarrollo de muchos territorios en Costa Rica desde 1949 y hasta los años ochenta.

Mientras el Estado y su aparato descentralizado facilitaron el desarrollo técnico en áreas productivas, las cooperativas permitieron el desarrollo grupal y empresarial que de manera combinada desarrollaron condiciones favorables en diferentes regiones del país.

Esa combinación entre políticas públicas, cooperativas e iniciativas productivas favoreció el crecimiento de importantes redes sociales que facilitaron la construcción de un capital social que de manera sostenida ha permitido el desarrollo los territorios y creado condiciones para que, de manera individual, colectiva, pública o privada; articule intercambios de riqueza y de bienestar entre actores locales.

Pese a lo anterior, debe indicarse que el cooperativismo alcanza esos niveles de impacto y de bienestar por el desarrollo pleno de la acción colectiva y de la gestión colectiva sostenidas. Las manifestaciones de una sola de esas categorías no genera condiciones estructurales en beneficio del desarrollo. Por el contrario la ausencia de una de ellas no facilita la distribución de la riqueza, la eficiencia en los 
procesos de inversión social y no hay seguridad de incrementar los niveles de impacto de las políticas públicas.

Bajo el anterior concepto, el cooperativismo alcanza la plenitud de los impactos y de bienestar en un territorio cuando sostiene condiciones de competitividad empresarial, cuando genera políticas para modernizar sus negocios, cuando diversifica sus productos y mantiene una política constante de crecimiento de sus activos en un marco de participación social. Con ello se favorece no solo la distribución de excedentes, sino que permite la búsqueda de equilibrios de ingreso en las cadenas productivas en que participa, aportando condiciones positivas para el desarrollo económico.

Ese desarrollo con equidad ha sido una realidad pese a las condiciones históricas que han enfrentado los pequeños productores en los territorios. En ese contexto, las cooperativas han funcionado como importantes agentes de distribución de recursos en las cadenas de valor desde actividades con excedente operativo hacia actividades con déficit operativo, facilitando una especie de amortiguamiento de las crisis que les permite mantenerse en los mercados.

Esa redistribución de recursos ha incidido en una importante área del desarrollo humano como es la sostenibilidad de los ingresos, trayendo consigo el establecimiento de una política de contención social y económica en la generación de capacidades adquisitivas. Esa contención ha generado que grupos numerosos de pequeños productores no queden tan expuestos a la fragilidad de los mercados, evitando su descenso bajo la línea de pobreza.

Es decir, las cooperativas materializan importantes roles proactivos en los territorios para la atención de grupos humanos que el Estado podría hacerlo a posteriori por la vía de políticas compensatorias, lo cual genera incontables ahorros en la inversión social y una mayor eficiencia en la gestión de políticas para esos grupos.

En materia de políticas públicas, la articulación de políticas sectoriales y territoriales son las que más incidencia tienen en el desarrollo en el mediano y largo plazos ya que permiten construir capital social. La apuesta por las políticas genéricas que actúan para mantener el funcionamiento de empresas no necesariamente atiende las condiciones estructurales requeridas para potenciar el modelo cooperativo, por ello una adecuada combinación de criterios es lo adecuado para impulsar integralmente el modelo.

En ese sentido, el uso de las cooperativas como instrumentos indirectos para la ejecución de políticas públicas debe considerar no solo el funcionamiento de la cooperativa como empresa en marcha sino también el funcionamiento del colectivo que le sostiene, su capital social, como una fuente importante de potencialidades que faciliten el desarrollo de los territorios de una forma distributiva, en beneficio de las personas, la razón de ser de toda acción política asociativa.

\section{Referencias Bibliográficas}

Aguilar, O., \& Fallas, C. L. (1990). El movimiento cooperativo en Costa Rica. Sus antecedentes en la historia universal. San José: 1 ed. Imprenta Nacional.

Castelao, M. C. (Enero- Junio 2009 de 2009). La economía social solidaria en las políticas pùblicas argentinas, ¿̇lnstrumento de política o alternativa socioeconómica? Un análisis preliminar. Revista Venezolana de Economía Social(17), 30-48.

Cepal. (1985). Cooperativismo y participación popular en América Latina y el Caribe: Reflexiones en busca de un enfoque para la Cepal.

Coque, J. (2002). Las cooperativa en América Latina: visión histórica y comentario de algunos países tipo. Revista de Economía Pública, Social y Cooperativa , 145-172.

Dussel, E. (2014). 16 Tesis de economía políica: interpretación filosófica. México : Siglo XXI Editores.

Facio, R. (1978). Obras de Rodrigo Facio Tomo I. Estudio sobre economia costarricense. San José Costa Rica: Editorial Costa Rica. 
Huaylupo, J. (2005). Tiempo-espacio-sociedad. Una perpectiva espistemológica para la interpretación de la sociedad y el estado. San José : Centro de Investigación y Capacitación en Investigación Pública .

Huaylupo, J. (2007). El capital social cooperativo: el caso de Coopeagri en Costa Rica. Unircoop, 76-102.

Programa Estado de la Nación. (2012). IV Censo Nacional Cooperativo (Vol. 1 a. ed.). San José: Instituto Nacional de Fomento Cooperativo.

Roivira, J. (2000). Estado y política econñomica en Costa Rica: 1948-1970. San José, Costa Rica: Editorial de la Universidad de Costa Rica.

Silva, W. P. (2002). De la colonización al desarrollo rural. IDA. Cuarenta años de paz social en Costa Rica, 1961-2001. Instituto de Desarrollo Agrario.

Wallerstein, I. (2013). El capitalismo histórico. México : Siglo XXI Editores, S.A. de C.V. 